\title{
Surfactant-mediated gene transfer for animal cells
}

\author{
Jun You, Masamichi Kamihira \& Shinji Iijima \\ Department of Biotechnology, Graduate School of Engineering, Nagoya University, Chikusa-ku, Nagoya 464-01, \\ Japan
}

Received 17 ebruary 1997; accepted 7 July 1997

Key words: cationic surfactant, DDAB, gene transfection, lipid vesicles

\begin{abstract}
A commercially available cationic surfactant, dimethyl-dioctadecyl ammonium bromide (DDAB), was used for making lipid vesicles. DDAB easily dissolved in water at $60^{\circ} \mathrm{C}$ and formed lipid vesicles at room temperature. The lipid vesicles showed very low cytotoxicity compared with other cationic surfactants. After the lipid vesicles were mixed with plasmid DNA solution, the solution was added to mammalian cells. The addition of a nonionic surfactant (Tween 80) to the cationic lipid vesicles at the weight ratio of 1:1 enhanced transfection efficiency. Adding more or less than the optimal amounts of DNA and lipid vesicles resulted in decreased transfection efficiency. With the optimal amounts of DNA (pCMV $\beta$ ) and lipid vesicles, about 90-95\% of CHO-K1 and BHK-21C13 cells transiently expressed $\beta$-galactosidase activity $24 \mathrm{~h}$ after transfection. By this procedure, stable transformants around $10^{5}$ cells corresponding to $10 \%$ efficiency could be obtained by one batch transfection.
\end{abstract}

Abbreviations: DDAB - dimethyl-dioctadecyl ammonium bromide; HTAB - hexadecyltrimethyl ammonium bromide; DMB - decamethonium bromide; CPC - cetylpyridinium chloride; MTAC - methyltrioctyl ammonium chloride; CDAB - cetyldimethylethyl ammonium bromide; CHO - Chinese hamster ovary; BHK - baby hamster kidney; CMV - cytomegalovirus

\section{Introduction}

DNA transfection of animal cells has become an important technique for analyses of gene function, production of recombinant gene products and the development of gene therapy. Although animal cells can take up exogenous DNA under appropriate conditions, the spontaneous uptake of intact DNA into cells and its subsequent expression in a nucleus is a very inefficient process due to the multitude of enzymatic and membrane barriers imposed by cells. Thus, a number of methods have been developed to facilitate this process to obtain both transient and stable expression of exogenous DNA. These include the use of polycations, liposomes, reconstituted viral envelopes and reagents such as calcium phosphate and DEAE-dextran (Klebe et al., 1984; Bond and Wold, 1987; Mannino and Fould-Fogerite, 1988). Physical approaches for introducing DNA such as microinjection, particle gun and electroporation (Potter et al., 1984) have been also used successfully. However, these procedures require a special device.

A recent addition to the repertoire of DNA transfection methodologies is cationic liposome-mediated transfection (lipofection) (Felgner et al., 1987; Felgner and Ringold, 1989; Malone et al., 1989; LeVentis and Silvius, 1990). Cationic liposomes spontaneously form complex with plasmid DNA or RNA in solution and facilitate fusion between the complex and cells in culture, resulting in the efficient transfer of nucleic acids to a wide variety of animal cell types. The possible use of cationic liposomes in the transfection has been the subject of numerous studies, and promising results from a human clinical study were published recently where the technique was employed in vivo (Nabel et al., 1993).

In the present study, we report a new DNAtransfection procedure using commonly available inex- 
pensive reagents for further development of alternative DNA transfer method for wide variety of purpose.

\section{Materials and methods}

\section{Cell lines, media and plasmid DNAs}

A Chinese hamster ovary CHO-K1, a baby hamster kidney BHK-21C13, and an African green monkey kidney COS-7 cell lines were obtained from RIKEN cell bank and used as host cells for gene transfection. CHO-K1 and COS-7 cells grew with an anchorage dependent manner and BHK-21C13 cells subcloned from anchorage dependent BHK-21 cells grew in suspension.

CHO-K1 cells were cultured in Ham's F12 medium (Gibco BRL Co., Grand Island, NY, USA) supplemented with $10 \%$ fetal bovine serum (FBS) (JRH Sciences, Lenexa, KS, USA). COS-7 cells were cultured in minimum essential medium (MEM) (Gibco BRL Co.) supplemented with $10 \%$ FBS. BHK-21C13 cells were cultured in MEM medium supplemented with $10 \%$ FBS and $1 \%$ non-essential amino acids (NEAA). The cells were cultured at $37{ }^{\circ} \mathrm{C}$ in a $5 \% \mathrm{CO}_{2}$ incubator. Media for all cultures routinely included 100 units $\mathrm{ml}^{-1}$ penicillin and $100 \mu \mathrm{g} \mathrm{ml}^{-1}$ streptomycin.

Recombinant plasmids, $\mathrm{pCMV} \beta$ (Macgregor and Caskey, 1989) and pCH110 (Hall et al., 1983), encoding lac $Z$ gene under the control of cytomegalovirus (CMV) early promoter and SV40 early promoter, respectively, were used for transient expression. A recombinant plasmid pMC1Neo (Toyobo Co., Osa$\mathrm{ka}$, Japan) encoding neo gene under the control of TK promoter was used for stable expression.

\section{Preparation of cationic lipid vesicles}

Commercially available cationic surfactants, dimethyldioctadecyl ammonium bromide (DDAB), hexadecyltrimethyl ammonium bromide (HTAB), decamethonium bromide (DMB), cetylpyridinium chloride (CPC), methyltrioctyl ammonium chloride (MTAC) and cetyldimethylethyl ammonium bromide (CDAB) were obtained from Sigma Chemical Co. (St. Louis, MO, USA) and used for making cationic lipid vesicles as a DNA carrier. Nonionic surfactants, NP-40 (Sigma Chemical Co.), Pluronic F-68 (BASF Japan Co., Osaka, Japan), Triton X-100 (Wako Pure Chemical Industries Co., Osaka, Japan), Tween 20 (Wako Pure Chemical Industries Co.) and Tween 80 (Wako Pure
Chemical Industries Co.) were employed as an additive for improvement of stability of lipid vesicles and transfection efficiency.

The surfactant was dissolved in water at $60^{\circ} \mathrm{C}$ or by sonication at room temperature. Then the surfactant solution $\left(1 \mathrm{mg} \mathrm{ml}^{-1}\right)$ was autoclaved at $120{ }^{\circ} \mathrm{C}$ for $20 \mathrm{~min}$, and preserved in a refrigerator. The solution was prewarmed and homogenized before use.

\section{Cytotoxic test of surfactants}

Cytotoxicity of cationic surfactant reagents was measured as follows. $\mathrm{CHO}-\mathrm{K} 1$ cells were plated at the cell density of $1.5 \times 10^{5}$ cells per a $35 \mathrm{~mm}$-dish and incubated at $37^{\circ} \mathrm{C}$ for $24 \mathrm{~h}$. Then the medium was changed in the presence of $2 \mu \mathrm{M}$ or $20 \mu \mathrm{M}$ cationic surfactant reagents. After $24 \mathrm{~h}$, the cells were trypsinized and stained with $0.1 \%$ trypan blue. The living cells were counted under a microscope.

\section{Transient transfection assay}

Cultured dishes with 50 to $70 \%$ confluent cells were rinsed twice with serum-free opti-MEM medium (Gibco BRL Co.) to remove serum from the culture. In the case of BHK-21C13 cells, the cells were collected and washed by centrifugation. The opti-MEM medium was removed just before the addition of the solution containing lipid vesicle/DNA complex. Typically, $3 \mu \mathrm{g}$ of DNA and $36 \mu \mathrm{g}$ of lipid vesicles which contained DDAB and Tween 80 at the weight ratio of 1:1 were used for transfection. They were diluted separately in $0.75 \mathrm{ml}$ opti-MEM medium, gently mixed and then stood at room temperature for about $30 \mathrm{~min}$ to form the complex. The solution containing the complex was added to the rinsed cells in a $35 \mathrm{~mm}$ diameter tissue culture dish (Iwaki Grass Works Co., Tokyo, Japan). After $6 \mathrm{~h}$ incubation, the DNA/lipid vesicle solution was removed and growth medium was added. Assay of transient expression of $\beta$-galactosidase was performed at 24 to $48 \mathrm{~h}$ post transfection.

In situ staining was performed to identify $\beta$ galactosidase expressed cells. Cells were rinsed twice with phosphate buffered saline (PBS), fixed with $2 \mathrm{ml}$ of $2 \%(\mathrm{v} / \mathrm{v})$ formaldehyde and $0.2 \%$ glutaraldehyde in PBS for $5 \mathrm{~min}$ at room temperature, rinsed twice with PBS, and then stained for $2 \mathrm{~h}$ to overnight with $2 \mathrm{ml}$ of $\mathrm{X}$-gal solution: $5 \mathrm{mM}$ potassium ferricyanide, $5 \mathrm{mM}$ potassium ferrocyanide, $2 \mathrm{mM}$ $\mathrm{MgCl}_{2}$, and $1 \mathrm{mg} \mathrm{ml}^{-1}$ 5-bromo-4-chloro-3-indolyl$\beta$-D-galactopyranoside (Wako Pure Chemical Indus- 
tries Co.) in PBS. Stained cells were counted under a microscope and the percentage of stained cells (transfection efficiency) was determined as the average of counts in three different fields.

\section{Stable transfection assay}

Complexes of plasmid DNA and lipid vesicles were prepared as mentioned for transient transfection. CHO$\mathrm{K} 1$ cells were plated at the cell density of $1.5 \times 10^{5}$ cells per a $35 \mathrm{~mm}$-dish on the day before transfection and incubated for $6 \mathrm{~h}$ with DNA/lipid vesicle solution containing $3 \mu \mathrm{g}$ pMC1Neo DNA and $36 \mu \mathrm{g}$ of lipid vesicles in $1.5 \mathrm{ml}$ opti-MEM serum free medium. Then the medium was changed to Ham's F12 medium supplemented with $10 \%$ FBS. Two days after the transfection the cells were diluted to $10^{-5}$ and seeded in a 96-wells tissue culture plate. Transformants were selected in the medium containing $400 \mu \mathrm{g} \mathrm{ml}^{-1}$ geneticin (Sigma Chemical Co.). After 2 weeks, cell colonies were fixed and stained with the solution containing $10 \%$ formaldehyde and $0.2 \%$ crystal violet in PBS for $2 \mathrm{~h}$ at room temperature. The plate was rinsed with water and the number of cell colony was counted after drying.

\section{Other measurement}

Average diameter of lipid vesicles was determined by a dynamic light scattering device (DLS-700, Ohtsuka Electronics Co., Osaka, Japan) and expressed as a Contin diameter.

\section{Results and discussion}

\section{Cytotoxicity and transfection efficiency of cationic surfactants}

Figure 1 shows cytotoxicity of six commercially available cationic surfactants for CHO-K1 cells. Except for DDAB and DMB, the four surfactants exhibited serious toxic effect for the cells at $20 \mu \mathrm{M}$ and most of cells died within a day. The toxic effect was alleviated very much by the decrease of concentration to $2 \mu \mathrm{M}$. However, CPC and MTAC still exhibited cytotoxicity and the cell viability was less than $20 \%$. The other surfactants were applied for gene transfection. For the transient transfection, plasmid DNA $(\mathrm{pCMV} \beta)$ and the respective surfactants were mixed, and the solution was added to the cell culture dish where the final sur-

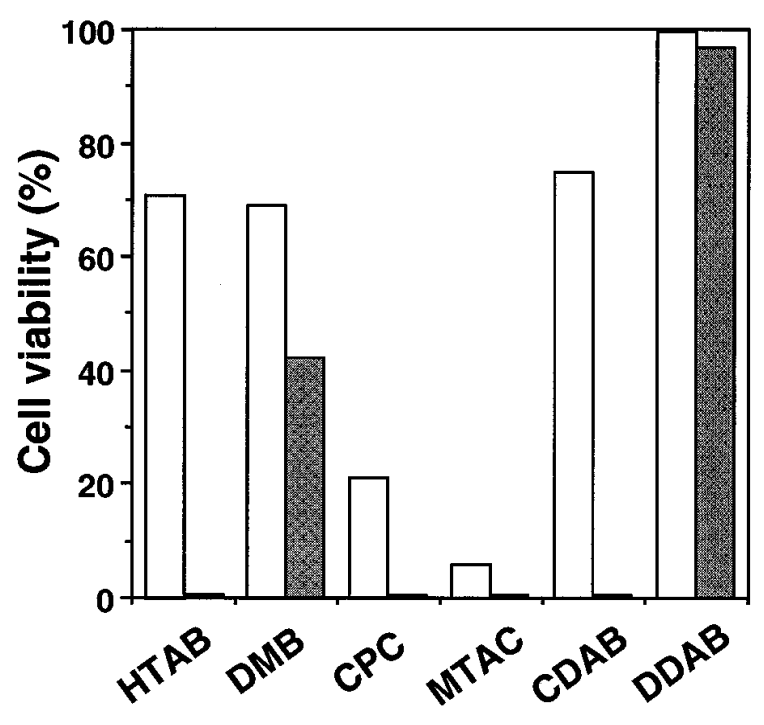

Figure 1. Comparison of cationic surfactants on cytotoxicity of CHO-K1 cells. The cationic surfactants were added to the culture medium at the concentration of $2 \mu \mathrm{M}(\square)$ and $20 \mu \mathrm{M}$ ( The cell viability was measured $24 \mathrm{~h}$ after the addition.

factant concentration was $2 \mu \mathrm{M}$. Only when DDAB was used as a DNA carrier, the cells took up the DNA and expression of lac $Z$ gene was observed. Thus, we assumed that DDAB formed a kind of complex with the plasmid DNA and promoted the cellular uptake of DNA.

Many surfactant mediated gene transfection procedures, which use commercial lipofection reagents (Holmen et al., 1995), synthetic cationic surfactants and natural phospholipids (Bennett et al., 1995), are now available. However, some of such reagents exhibited cytotoxic effect even in the effective concentration for gene transfection (Yagi et al., 1993). DDAB has been also used for gene transfection as a DNA carrier (Rose et al., 1991; Lappalainen et al., 1994). In those cases, DDAB was mixed with dioleoyl-phosphatidylethanolamine (DOPE) at molar ratio of $1: 1$ or $1: 2.5$ to enhance transfection efficiency, and toxic effect on CaSki cells at $10 \mu \mathrm{M}$ was reported (Lappalainen et al., 1994). In addition, the procedure for making lipid vesicles requires an evaporator and a sonicator.

As shown in Fig. 1, DDAB itself seemed to have low cytotoxicity for animal cells compared with other cationic surfactants. Therefore, the effect of DDAB concentration on viability of CHO-K1 cells was examined as shown in Fig. 2. More than $95 \%$ of the cells was viable at the concentrations up to $20 \mu \mathrm{M}$. The cell viability decreased when the concentration increased 


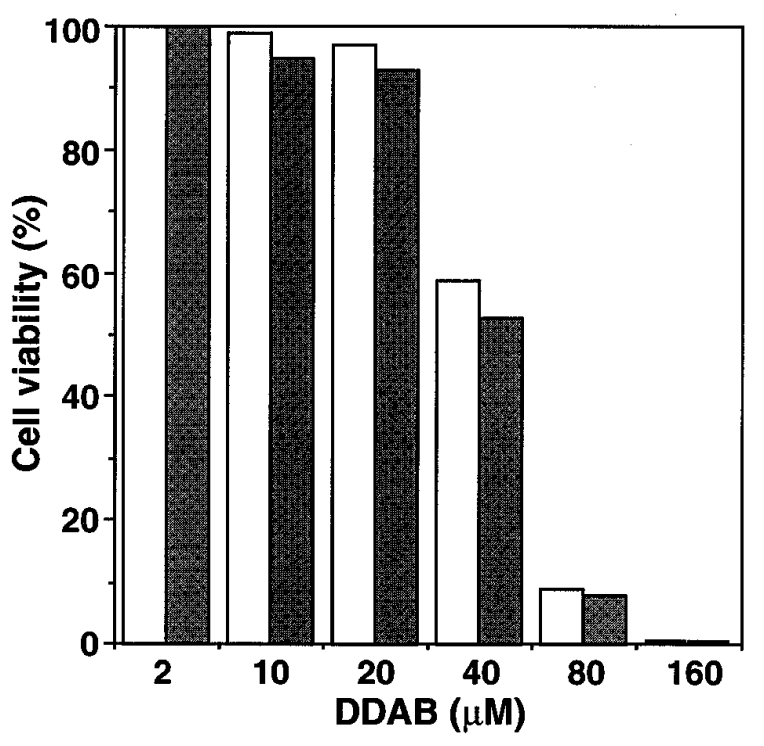

Figure 2. Cytotoxicity of DDAB lipid vesicles on CHO-K1 cells. Lipid vesicles consisting of only DDAB $\square$ ) or DDAB + Tween 80 $(1: 1, w / w)($ were added. The cell viability was measured $24 \mathrm{~h}$ after the addition.

more than $40 \mu \mathrm{M}$. Almost all the cells tested died with $160 \mu \mathrm{M}$ of the surfactant. Nevertheless, DDAB had low cytotoxicity to animal cells compared with the surfactants used in gene transfection including commercial lipofection reagents and natural phospholipids (Yagi et al., 1993; Lappalainen et al., 1994).

\section{Effect of nonionic surfactant addition on transfection efficiency}

The mechanism of gene expression in surfactant mediated gene transfer is assumed as follows. Cationic surfactants form lipid vesicles which have positive charges on the surface. Since DNAs have negative charges, the lipid vesicles form some complex with DNAs. Normally animal cell surface also has negative charges derived from sialic acid residues, hence the positive charges of lipid vesicles interact with cell surface and lipid vesicle/DNA complex binds to cell surface. Then cells take up the complex by endocytosis. The incorporated DNA is transferred to nucleus of a cell and gene product is expressed. Generally, the processes of the formation of lipid vesicle/DNA complex and the endocytosis of the complex are important in surfactant mediated gene transfection. In this regards, dispersion condition of lipid vesicles seems to be crucial for the complex formation. DDAB lipid vesicles tended to aggregate at high concentration especially in low temperature. When DDAB formed aggregation, effective lipid vesicle concentration reduced and transfection efficiency decreased. In order to stabilize DDAB lipid vesicles for prevention of the aggregation and facilitate endocytosis of the cells, the addition of nonionic surfactant to DDAB lipid vesicles was examined (Fig. 3). Commonly used five nonionic surfactants (NP-40, Triton X-100, Pluronic F-68, Tween 20 and $80)$ were added at the weight ratio of $1: 1$ to DDAB. After mixed with plasmid DNA ( $\mathrm{pCMV} \beta$ ) solution, transient transfection efficiency was measured with three cell lines. As shown in Fig. 3, the addition of nonionic surfactant to DDAB for the preparation of lipid vesicles influenced transfection efficiency; some nonionic surfactants enhanced the efficiency. However, these effects depended on cell line. Tween 80 and Pluronic F-68 had positive effects on transfection for all the cell lines tested. In particular, by the addition of Tween 80 to DDAB lipid vesicles, 85 and $92 \%$ of CHO-K1 and BHK-21C13 cells expressed the transfected gene. In addition to the improved transfection efficiency, the lipid vesicles were stabilized. Average diameter of DDAB lipid vesicles was $500-600 \mathrm{~nm}$ by dynamic light scattering method without Tween 80 , but the diameter was decreased to $100-200 \mathrm{~nm}$ by the addition of the surfactant. This indicates that Tween 80 may act as a dispersing agent of DDAB lipid vesicles and the positive effects of Tween 80 may be due to the stabilization of the lipid vesicles. From these results, Tween 80 was used as an additive to DDAB lipid vesicles in further study.

To optimize the Tween 80 addition, we studied whether the transfection efficiency was influenced by the ratio of Tween 80 and DDAB (Fig. 4). In this experiment, the concentration of DDAB was fixed at $2 \mu \mathrm{M}$. As the ratio of Tween 80 increased to equal amount (Tween $80 / \mathrm{DDAB}=1$ ), transfection efficiency increased for all the cell lines tested. Above the equal ratio, the efficiency gradually decreased. The tendency was the same for the three cell lines and over the variety of DNA concentration, although the expression level was different with cell lines. In all cases tested, the maximum transfection efficiency was obtained when the ratio of Tween 80 to DDAB was around 1. Moreover, cytotoxicity of DDAB was not enhanced by the addition of Tween 80 (Fig. 2).

\section{Optimization of transfection efficiency}

As reported earlier (Felgner et al., 1987; Felgner and Ringold, 1989), gene transfection using cationic lipo- 


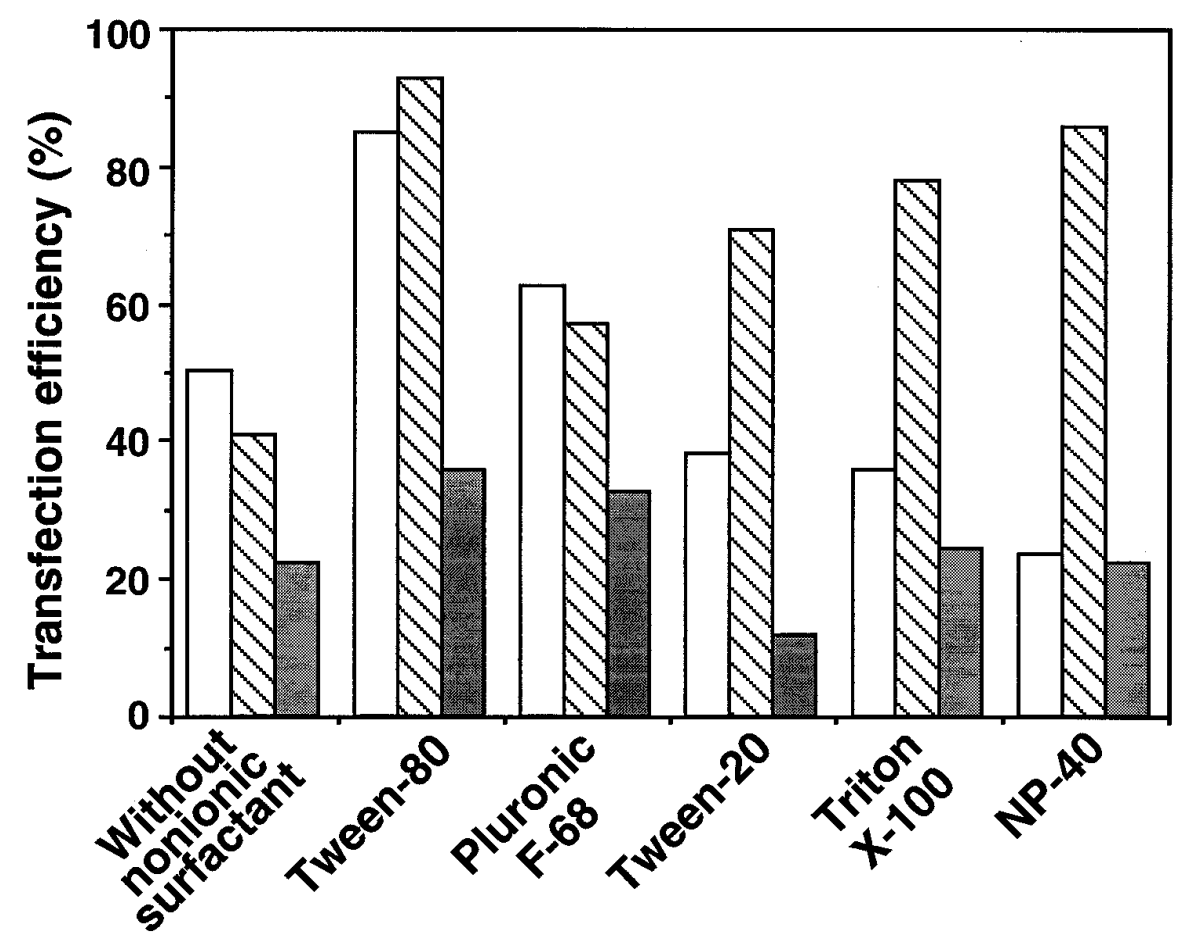

Figure 3. Effect of nonionic surfactant on transfection efficiency in the presence of DDAB lipid vesicles. Five nonionic surfactants were added at the weight ratio of 1:1 to DDAB. CHO-K1 $\square$ ), BHK-21C13 $\mathbb{\mathbb { N }}$ ) and COS-7 ) cells were applied for transfection of pCMV $\beta$.
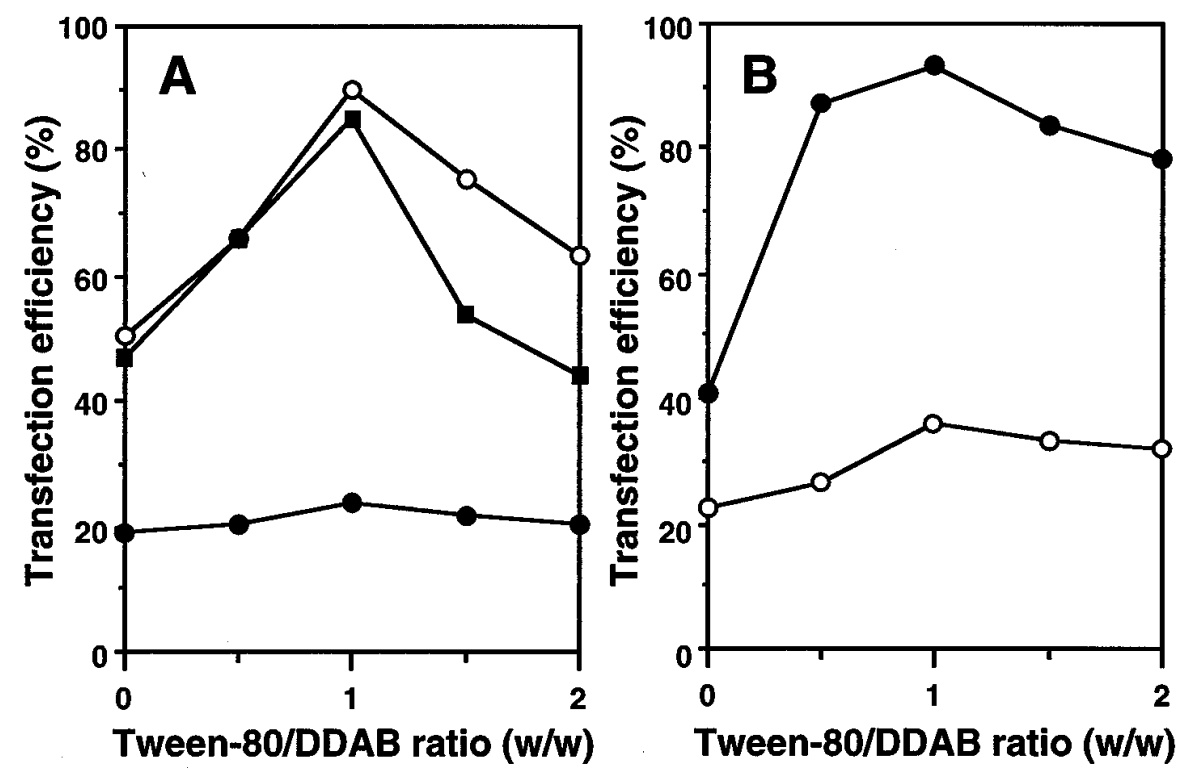

Figure 4. Effect of Tween 80 and lipid vesicles ratio on transfection efficiency. (A) CHO-K1 cells were applied for transfection of $1 \mu \mathrm{g}(\bullet)$,

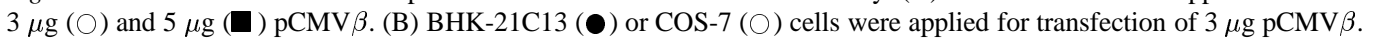


somes as DNA carrier was influenced by many conditions such as concentrations of lipid vesicles and DNA, medium, cell density and cell type. In the present study, a serum-free medium should be used for incubation of the cells with lipid vesicle/DNA complexes to obtain high transfection efficiency. In the other transfection procedures including lipofection, the use of a serum-free medium is often crucial for obtaining good result (Felgner et al., 1987). Some serum components may weaken interaction between lipid vesicles and DNA or cells. A variety of serum-free medium showed enhanced transfection efficiency with the present method. Among those, opti-MEM medium gave the best results with respect to cell viability during transfection, the efficiency and the reproducibility (data not shown).

For further optimization of transfection condition, the amounts of DNA and lipid vesicles added to the medium were examined (Fig. 5). In this experiment, Tween 80 was added to DDAB lipid vesicles at the same weight ratio. The optimal amount of lipid vesicles existed depending on the amount of DNA, indicating that the ratio of DNA and lipid vesicles was important. At low amounts of DDAB relative to DNA, the transfection efficiency increased with increase in the amount of lipid vesicles added. After reaching the maximum, it gradually decreased. Thus, excess lipid vesicles resulted in decreased transfection efficiency. These suggest that the lipid vesicles facilitate the DNA uptake, but the excess lipid vesicles interfere the DNA uptake. The optimal amounts of lipid vesicles in which transfection efficiency became the maximum were 24 and $36 \mu \mathrm{g}$ for 2 and $3 \mu \mathrm{g}$ DNA, respectively, per a $35 \mathrm{~mm}$-dish. The optimal DNA/lipid vesicles ratio for 2 and $3 \mu \mathrm{g}$ DNA was 0.083 ( $\mu \mathrm{g}-\mathrm{DNA} / \mu \mathrm{g}$-lipid vesicles). Although the optimal amounts of DNA and lipid vesicles are changed by culture scale, DNA/lipid vesicles ratio may be a good index for scale-up or down of transfection.

As shown in Fig. 5, the optimal amounts of lipid vesicles for each DNA amount were almost the same independent of cell line, but the behavior of the transfection efficiency on the variation of lipid vesicles amount was slightly different between the cell lines; the efficiency strongly depended on the amount of DNA and lipid vesicles with CHO-K1 cells, whereas the dependency was less with BHK-21C13 cells. To obtain the maximum transfection efficiency, appropriate amount of DNA is necessary, because low DNA amount causes lack of DNA and high DNA causes toxic effect for cells. In all cases, $3 \mu \mathrm{g}$ of plasmid DNA per a
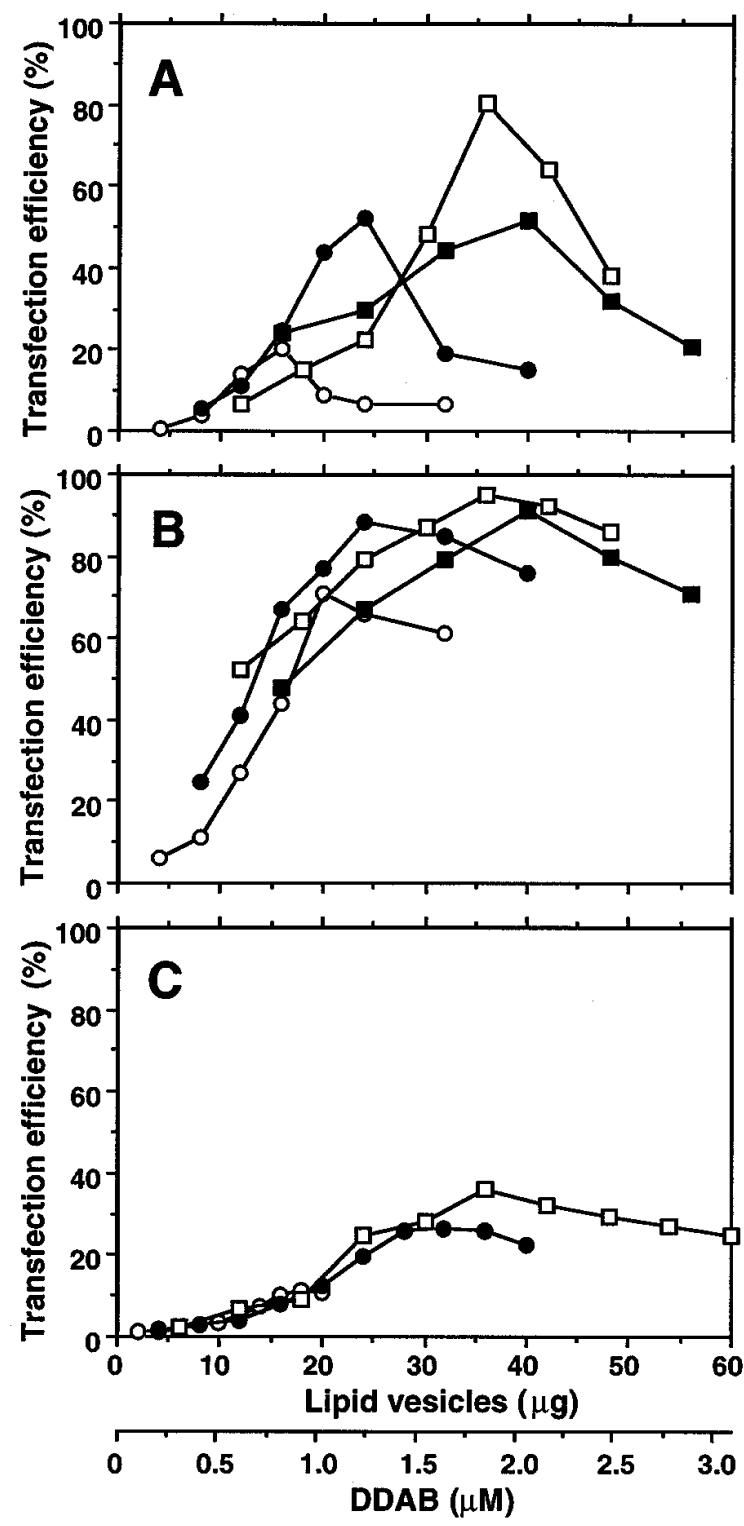

Figure 5. Effect of DNA and lipid vesicles amounts on transfection efficiency. CHO-K1 (A), BHK-21C13 (B) or COS-7 (C) cells were applied for transfection of $1 \mu \mathrm{g}(\bigcirc), 2 \mu \mathrm{g}(\bullet), 3 \mu \mathrm{g}(\square)$ and $4 \mu \mathrm{g}$ (口) $\mathrm{pCMV} \beta$.

$35 \mathrm{~mm}$-dish and $36 \mu \mathrm{g}$ of lipid vesicles gave the highest efficiency. Under the optimal condition, the maximum transfection efficiency more than $90 \%$ was obtained for $\mathrm{CHO}-\mathrm{K} 1$ and BHK-21C13 cells (Fig. 6). The level of the transfection efficiency was more than 10-fold higher than conventional calcium phosphate method and comparable to commercial lipofection procedure. 


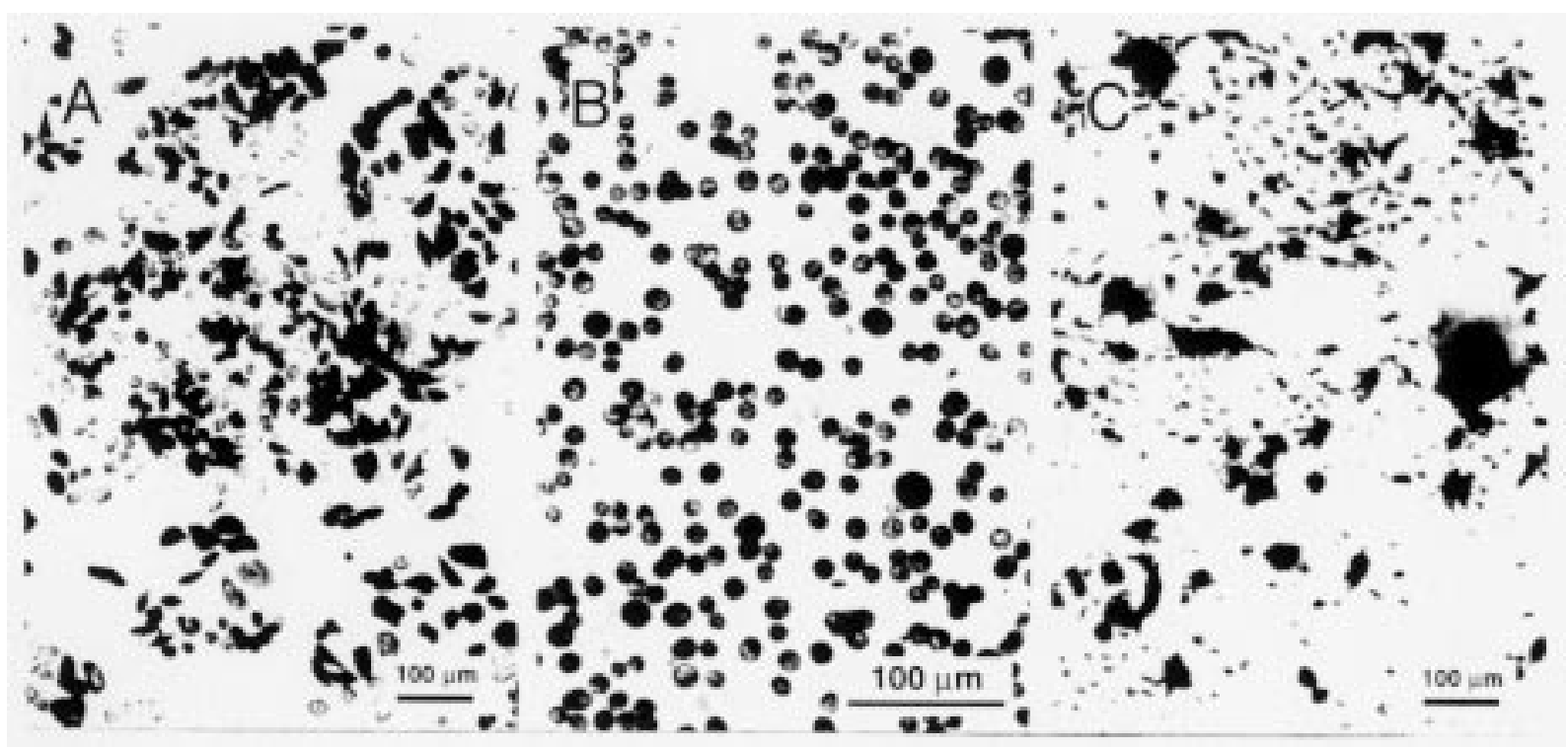

Figure 6. Photographs of $\beta$-galactosidase expressing cells after transfection (Stained with X-gal). CHO-K1, BHK-21C13 and COS-7 cells were plated at the cell density of $1.5 \times 10^{5}, 2 \times 10^{6}$ and $1.5 \times 10^{5}$ cells per a $35 \mathrm{~mm}$-dish on the day before transfection. pCMV $\beta(3 \mu \mathrm{g})$ and lipid vesicles $(36 \mu \mathrm{g})$ consisting of DDAB and Tween 80 at the weight ratio of 1:1 were used for transfection. (A) CHO-K1, (B) BHK-21C13, (C) COS-7.

Table 1. Transfection efficiency under the optimal conditions

\begin{tabular}{llll}
\hline \multirow{2}{*}{ Plasmid DNA } & \multicolumn{3}{l}{ Transfection efficiency (\%) } \\
\cline { 2 - 4 } & CHO-K1 & BHK-21C13 & COS-7 \\
\hline \multirow{2}{*}{ CMV $\beta$} & 90 & 95 & 36 \\
pCH110 & 23 & 86 & 19 \\
\hline
\end{tabular}

Transfection conditions: CHO-K1, BHK-21C13 and COS7 cells were plated at the cell density of $1.5 \times 10^{5}, 2 \times 10^{6}$ and $1.5 \times 10^{5}$ cells per a $35 \mathrm{~mm}$-dish on the day before transfection. The plasmid DNA ( $3 \mu \mathrm{g})$ and lipid vesicles $(36 \mu \mathrm{g})$ consisting of DDAB and Tween 80 at the weight ratio of $1: 1$ were used for transfection.

This procedure was to applied to other vectors, pCH110 for transient expression and pMC1Neo for stable expression. Table 1 summarizes transfection efficiencies for transient expression under the optimal conditions determined by using $\mathrm{pCMV} \beta$. Although the maximum transfection efficiency was different depending on plasmids and cell lines, the expression level was still high. The transfection procedure could be applied for stable expression and a great number of stable transformants around $10^{5}$ corresponding to about $10 \%$ efficiency could be obtained in one batch transfection (per a $35 \mathrm{~mm}$-dish) by using pMC1Neo plasmid and $\mathrm{CHO}-\mathrm{K} 1$ cells.
In conclusion, we developed a surfactant mediated gene transfection procedure using commonly available cationic and nonionic surfactants. The advantages of this transfection procedure are as follows. (1) The preparation of lipid vesicles as DNA carrier is very easy. (2) The lipid vesicles are autoclavable for sterilization. (3) The transfection procedure is also very simple without a special device. (4) Under the optimal conditions, high transfection efficiency could be obtained. (5) The lipid vesicles are low toxic for animal cells. Using these advantages, we will modify the lipid vesicles with some ligands for enhanced and/or cell-specific gene transfection. Furthermore, in vivo gene transfection will be also possible due to the low toxicity.

\section{Acknowledgments}

The authors wish to thank Dr. Toyoko Imae, Dept. of Physical Chemistry, School of Science, Nagoya University for advice in the measurement of the diameter of lipid vesicles using a dynamic light scattering device. This work was partially supported by CibaGeigy Foundation (Japan) for the Promotion of Science. 


\section{References}

Bennett MJ, Nantz MH, Balasubramaniam RP, Gruenert DC and Malone RW (1995) Cholesterol enhances cationic liposomemediated DNA transfection of human respiratory epithelial cells. Biosci Rep 15: 47-53.

Bond VC and Wold B (1987) Poly-L-ornithine-mediated transformation of mammalian cells. Mol Cell Biol 7: 2286-2293.

Felgner PL, Gadek TR, Holm M, Roman R, Chan HW, Wenz M, Northrop JP, Ringold GM and Danielsen M (1987) Lipofection: a highly efficient, lipid-mediated DNA-transfection procedure. Proc Natl Acad Sci USA 84: 7413-7417.

Felgner PL and Ringold GM (1989) Cationic liposome-mediated transfection. Nature 337: 387-388.

Hall CV, Jacob PE, Ringold GM and Lee F (1983) Expression and regulation of Escherichia coli lacZ gene fusions in mammalian cells. J Mol Appl Genet 2: 101-109.

Holmen SL, Vanbrockin MW, Eversole RR, Stapleton SR and Ginsberg LC (1995) Efficient lipid-mediated transfection of DNA into primary rat hepatocytes. In Vitro Cell Dev Biol 31: 347-351.

Klebe RJ, Harriss JV, Hanson DP and Gauntt CJ (1984) Highefficiency polyethylene glycol-mediated transformation of mammalian cells. Som Cell Mol Genet 10: 495-502.

Lappalainen K, Jaaskelainen I, Syrjanen K, Urtti A and Syrjanen S (1994) Comparison of cell proliferation and toxicity assays using two cationic liposomes. Pharmaceu Res 11: 1127-1131.

LeVentis R and Silvius JR (1990) Interactions of mammalian cells with lipid dispersions containing novel metabolizable cationic amphiles. Biochim Biophys Acta 1023: 124-132.
Macgregor GR and Caskey CT (1989) Construction of plasmids that express $E$. coli $\beta$-galactosidase in mammalian cells. Nucleic Acids Res 17: 2365.

Malone RW, Felgner PL and Verma IM (1989) Cationic liposomemediated RNA transfection. Proc Natl Acad Sci USA 86: 60776081.

Mannino RJ and Fould-Fogerite S (1988) Liposome mediated gene transfer. Biotechniques 6: 682-690.

Nabel GJ, Nabel EG, Yang ZY, Fox B, Plautz GE, Gao X, Huang L, Shu S, Gordon D and Chang AE (1993) Direct gene transfer with DNA- liposome complexes in melanoma: Expression, biologic activity, and lack of toxicity in humans. Proc Natl Acad Sci USA 1023: 124-132.

Potter H, Weir L and Leder P (1984) Enhancer-dependent expression of human kappa immunoglobulin genes introduced into mouse pre-B lymphocytes by electroporation. Proc Natl Acad Sci USA 81: 7161-7165.

Rose JK, Buonocore L and Whitt MA (1991) A new cationic liposome reagent mediating nearly quantitative transfection of animal cells. Biotechniques 10: 520-525.

Yagi K, Noda H, Kurono M and Ohishi N (1993) Efficient gene transfer with less cytotoxicity by means of cationic multilamellar liposomes. Biochem Biophys Res Commun 196: 1042-1048.

Address for correspondence: Masamichi Kamihira, Department of Biotechnology, Graduate School of Engineering, Nagoya University, Chikusa-ku, Nagoya 464-01, Japan. 